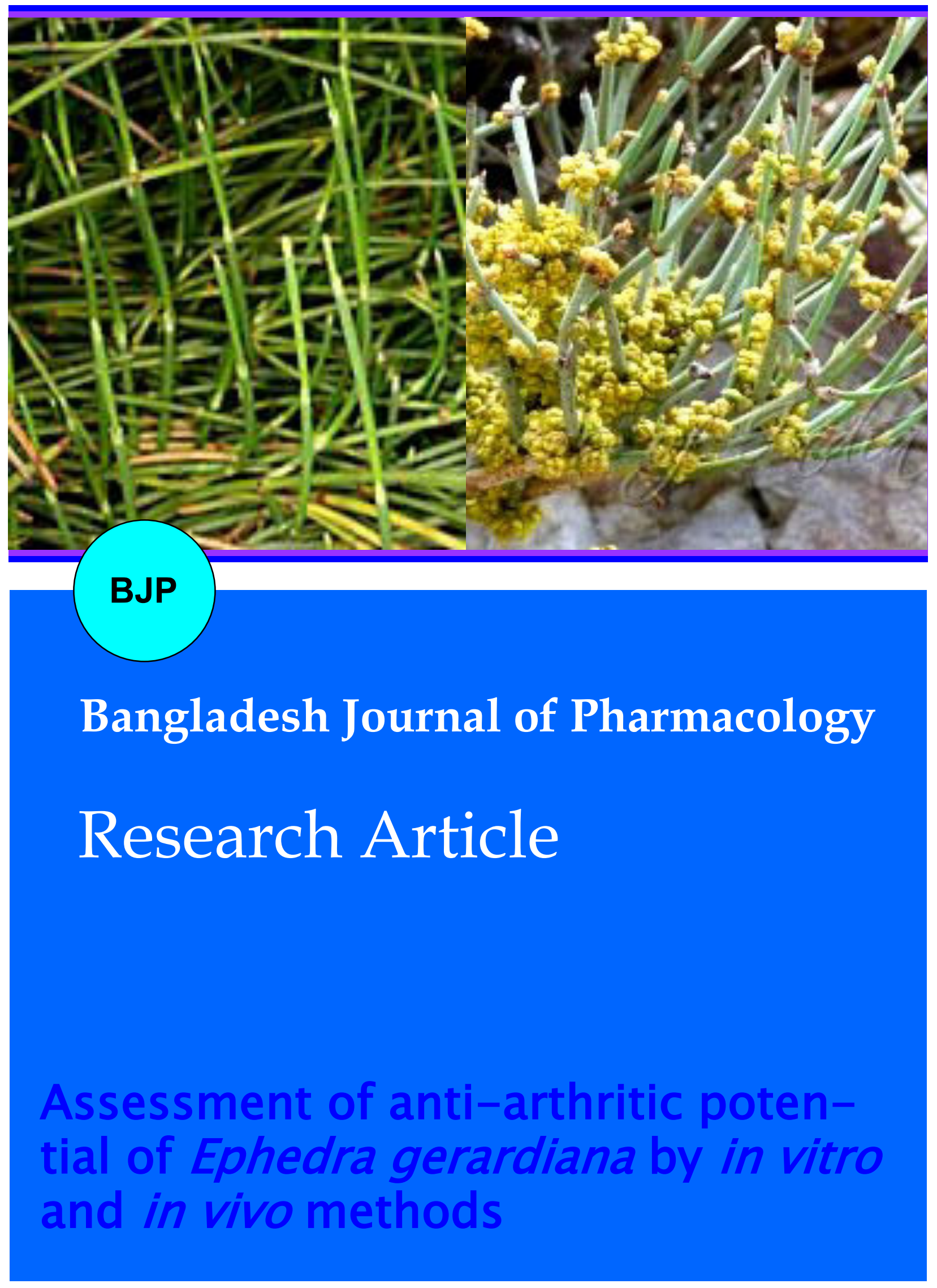




\title{
Assessment of anti-arthritic potential of Ephedra gerardiana by in vitro and in vivo methods
}

\author{
Ambreen Malik Uttra and Alamgeer
} Laboratory of Cardiovascular Research and Integrative Pharmacology, Department of Pharmacology, Faculty of
Pharmacy, University of Sargodha, Pakistan.

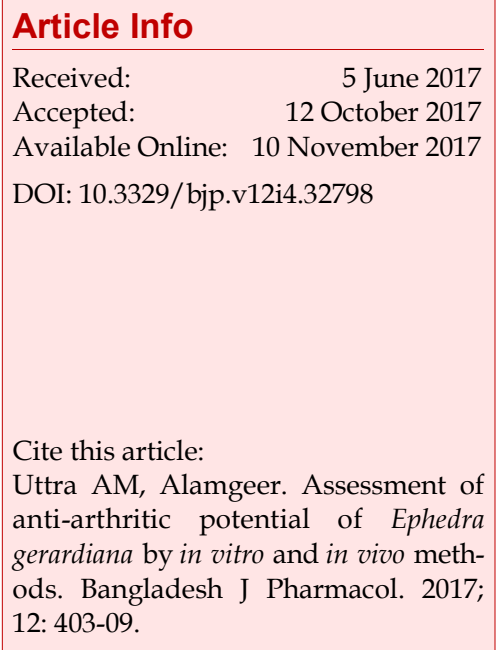

\begin{abstract}
The present study determines the anti-arthritic potential of Ephedra gerardiana ethanolic extract and its ethyl acetate, $n$-butanol and aqueous fractions adopting in vitro and in vivo tests. In vitro tests included thermally induced bovine serum albumin denaturation and egg albumin denaturation, also membrane stabilizing assay at concentration of $50-6400 \mu \mathrm{g} / \mathrm{mL}$, whereas in vivo study comprised formaldehyde-induced arthritis at 50, 100 and $200 \mathrm{mg} /$ $\mathrm{kg}$ doses. The crude extract and fractions inhibited protein denaturation and stabilized red blood cells membrane in concentration-dependent fashion, with maximal effect achieved at $6,400 \mu \mathrm{g} / \mathrm{mL}(\mathrm{p}<0.001)$. Similarly, in formaldehyde model, the extract and fractions dose-dependently reduced injected paw volume and diameter, with maximum reduction at $200 \mathrm{mg} / \mathrm{kg}(\mathrm{p}<0.001)$. However, results of aqueous fraction were on a par with hydroalcoholic extract in each test. These results suggest that E. gerardiana provides protection against arthritis that might be owing to the existence of phytoconstituents thus, supporting folkloric claim.
\end{abstract}

\section{Introduction}

Rheumatoid arthritis is a systemic autoimmune ailment and most imperative inflammatory arthritis in humans. The cause of rheumatoid arthritis is unknown.

Synthetic drugs employed to treat rheumatoid arthritis include NSAIDs, IL-1 receptor antagonist, DMARDs, anti-TNF-a drugs and glucocorticoids. Nevertheless, their use is accompanied with surplus adverse effects comprising immunosuppression and advent of opportunistic infections. Thus, the need of hour is to develop novel, long acting anti-arthritic agents with least adverse effects.

Patients with rheumatoid arthritis are among highest consumers of complementary and alternative medications and they pursue alternative methods for symptomatic relief. Natural herbs offer better results to mankind in dealing with this looming disease and plant derived drugs have attained admiration in last few years both in developing and developed countries owing to their natural origin and fewer adverse effects (Nair et al., 2011).

The Ephedraceae family contains 45 species of Ephedra genus that are native to sub-tropical and temperate areas of Europe, Asia, Central and North America (Ratsch, 1998). In Pakistan, Ephedra gerardiana Wall [Local name: Asmani Booti, Sopat, Soopt (Urdu), Sopt, Soom (Shina)], is found mostly in Northern areas of Pakistan, where local people commonly use whole plant, roots and stem for treating rheumatism and painful joints (Qureshi et al., 2006; Gorsi and Miraj, 2002). It is also used in respiratory tract infections, bone fractures, heart diseases and syphilis (Qureshi et al., 2006). Since, no pharmacological data is available on $E$. gerardiana to the best of our knowledge, a study was piloted to appraise its potential anti-arthritic effect 
employing both in vitro and in vivo procedures.

\section{Materials and Methods}

\section{Plant collection and identification}

E. gerardiana aerial parts were attained from Northern areas of Pakistan and were identified by Dr. Shair Wali Khan, Department of Botany, Karakoram International University of Gilgit Baltistan Pakistan. For future reference, voucher sample (No. EG-15-18) was placed in herbarium of Faculty of Pharmacy, University of Sargodha.

\section{Preparation of extract and fractions}

Dried and coarsely grounded aerial parts (stems and leaves) of E. gerardiana was extracted by cold maceration process using $10 \mathrm{~L}(70: 30, \mathrm{v} / \mathrm{v}$ ratio of ethanol to distilled water) solvent and was soaked at room temperature for 3 days. After 72 hours of intermittent stirring on daily basis, entire substance was strained first using cotton cloth and thereafter via filter paper (Whatman No. 1). This technique was done again three times and collective filtrate on a rotary evaporator $\left(40-50^{\circ} \mathrm{C}\right)$ was evaporated under reduced pressure $(-760$ $\mathrm{mm} \mathrm{Hg}$ ). The plant extract was further air-dried to acquire thick, semi-solid material, providing $21.3 \%$ yield. Activity directed fractionation of crude extract (130 g) was achieved using various organic solvents (dichloromethane, $n$-hexane, ethyl acetate and $n$ butanol). The yield of dichloromethane $(1.5 \%)$ and $n$ hexane $(2.3 \%)$ was very low so, only aqueous $(67.7 \%), n$ -butanol (16.9\%) and ethyl acetate (11.5\%) fractions were used to perform activities (Alamgeer et al., 2016). The solutions of test substances were made in distilled water to carry out all the experiments.

\section{Chemicals}

The chemicals used in this study were: ethanol, dichloromethane (Sigma-Aldrich, USA), $n$-hexane (Sigma-Aldrich, USA), $n$-butanol (Sigma-Aldrich, USA), ethyl acetate (Sigma-Aldrich, USA), bovine serum albumin (Sigma-Aldrich, USA), egg albumin from fresh hen's egg, disodium hydrogen phosphate (Merck, Germany), sodium chloride (Sigma-Aldrich, USA), formaldehyde (VWR, England), aspirin (UNI-CHEM, Germany), sodium hydroxide (Sigma-Aldrich, USA), potassium dihydrogen phosphate (Riedel-de-Haën, USA), diclofenac sodium (Sigma-Aldrich, USA) and piroxicam (Sigma-Aldrich, USA).

\section{Experimental animals}

Young and healthy male and female Sprague Dawley rats were used. The animals were kept in controlled temperature $\left(23\right.$ to $\left.25^{\circ} \mathrm{C}\right)$ and in 12 hours light and dark cycle at animal house, Faculty of Pharmacy, University of Sargodha. Animals were fed with standard pellet diet and water ad libitum.

\section{Egg albumin denaturation inhibition}

The $5 \mathrm{~mL}$ of test solution contained $0.2 \mathrm{~mL}$ of fresh hen's egg albumin, phosphate buffer of pH $6.4(2.8 \mathrm{~mL})$ and $2 \mathrm{~mL}$ of various concentrations $(50-6400 \mu \mathrm{g} / \mathrm{mL})$ of crude extract, aqueous, $n$-butanol and ethyl acetate fractions and standard drug (diclofenac sodium), respectively. Double-distilled water in similar quantity worked as control. The mixtures for $15 \mathrm{~min}$ were incubated at $37 \pm 2^{\circ} \mathrm{C}$ and next heated for $5 \mathrm{~min}$ at $70^{\circ} \mathrm{C}$. The absorbance was assessed at $660 \mathrm{~nm}$, after cooling. The inhibition percentage of egg albumin denaturation was figured out as under (Alamgeer et al., 2015).

Inhibition percentage $=[($ Absorbance control Absorbance test sample) /Absorbance control] $\times 100$

\section{BSA denaturation inhibition}

In order to estimate in vitro anti-arthritic efficacy, protein denaturation inhibition technique was adopted (Narayani et al., 2014). Different concentrations (50, 100, $200,400,800,1600,3200,6400 \mu \mathrm{g} / \mathrm{mL}$ ) of hydroalcoholic extract, fractions (aqueous, $n$-butanol, ethyl acetate) and reference drug (aspirin) were prepared, respectively. 0.5 $\mathrm{mL}$ of test control solution comprised $5 \% \mathrm{w} / \mathrm{v}$ aqueous solution of bovine serum albumin, BSA $(0.45 \mathrm{~mL})$ and $0.05 \mathrm{~mL}$ distilled water. Similarly, $0.5 \mathrm{~mL}$ product control solution contained test solution $(0.05 \mathrm{~mL})$ and distilled water $(0.45 \mathrm{~mL})$. Moreover, $0.5 \mathrm{~mL}$ test solution consisted of BSA $(0.45 \mathrm{~mL})$ and test solution $(0.05 \mathrm{~mL})$. The $0.5 \mathrm{~mL}$ standard solution included aspirin $(0.05$ $\mathrm{mL})$ and BSA $(0.45 \mathrm{~mL})$. The $\mathrm{pH}$ of aforementioned solutions was altered to 6.3 via $1 \mathrm{~N} \mathrm{HCl}$. Later, for 20 $\mathrm{min}$, the solutions were incubated at $37^{\circ} \mathrm{C}$ and then for $3 \mathrm{~min}$ heated at $57^{\circ} \mathrm{C}$. Thereafter, preceding mixtures were supplemented with phosphate buffer $(2.5 \mathrm{~mL})$ after cooling. The absorbance at $660 \mathrm{~nm}$ was evaluated through UV-Visible spectrophotometer and inhibitory percentage of BSA denaturation was calculated as under:

Inhibition percentage $=100-[($ Abs TS $-\mathrm{Abs}$ PC $) / \mathrm{Abs}$ $\mathrm{TC}] \times 100$

Where,

Abs=Absorbance, TS=Test solution, PC=Product control, $\mathrm{TC}=$ Test control

\section{Human red blood cell (HRBC) membrane stabilization assay}

Healthy humans who did not take NSAID'S atleast 2 weeks before conducting experiment donated the blood, which was combined with similar quantity of Alsever's solution. The centrifugation of this solution at $3,000 \mathrm{rpm}$ was then done. Packed cells were removed, rinsed with normal saline and a suspension of $10 \% \mathrm{v} / \mathrm{v}$ human red blood cell was made with normal saline. 
Test solution contained $2 \mathrm{~mL}$ hypotonic saline, phosphate buffer $(1 \mathrm{~mL}), 0.5 \mathrm{~mL}$ test samples at several concentrations (50, 100, 200, 400, 800, 1600, 3200, 6400 $\mu \mathrm{g} / \mathrm{mL})$, correspondingly and $0.5 \mathrm{~mL}$ of $10 \% \mathrm{v} / \mathrm{v}$ HRBCs. Similarly, test control comprised $2 \mathrm{~mL}$ distilled water, phosphate buffer $(1 \mathrm{~mL})$ and $10 \% \mathrm{v} / \mathrm{v}$ HRBCs $(0.5 \mathrm{~mL})$. Further, standard solution comprised $0.5 \mathrm{~mL}$ of $10 \% \mathrm{v} / \mathrm{v}$ HRBCs, $2 \mathrm{~mL}$ of hypotonic saline, phosphate buffer $(1 \mathrm{~mL})$ and $0.5 \mathrm{~mL}$ of diclofenac sodium at same concentrations. The test solutions for 30 min were incubated at $37^{\circ} \mathrm{C}$ and centrifuged at 3000 rpm. The spectrophotometer at $560 \mathrm{~nm}$ was used to estimate hemoglobin content in supernatant. The percentage membrane stabilization was worked out by under mentioned formula (Alamgeer et al., 2015):

Percentage membrane stabilization $=100$ - [(Sample optical density / Control optical density) $\times 100]$

\section{Formaldehyde-induced arthritis}

Animals were alienated into various groups of $n=5$. Group A received distilled water $(3 \mathrm{~mL} / \mathrm{kg})$ only, Group B received $10 \mathrm{mg} / \mathrm{kg}$ piroxicam, Groups C, D, E were given $50,100,200 \mathrm{mg} / \mathrm{kg}$ of E. gerardiana crude extract, separately, Groups F, G, H were treated with $50,100,200 \mathrm{mg} / \mathrm{kg}$ of aqueous fraction, corresponddingly, Groups I, J, K received 50, 100, $200 \mathrm{mg} / \mathrm{kg}$ of $n$ butanol fraction, accordingly and Groups L, M, N were administered 50, 100, $200 \mathrm{mg} / \mathrm{kg}$ of ethyl acetate fraction, respectively. The test solutions were administered orally to rats. On the day first, $30 \mathrm{~min}$ subsequent to oral administration of test substance, acute nonimmunological arthritis was prompted via sub planter injection of formaldehyde $2 \%(0.1 \mathrm{~mL})$, which was repeated on third day. Drug treatment continued for 10 days. Arthritis was appraised by determining paw volume using digital plethysmometer (Alamgeer et al., 2017). The percentage inhibition of paw volume by plant extract, fractions and piroxicam was equated with arthritic control.

$\%$ inhibition $=\frac{V c-V t}{V_{c}} \times 100$

$\mathrm{Vc}=$ Paw volume of control, $\mathrm{Vt}=\mathrm{Paw}$ volume of treated

\section{Statistical analysis}

The results were described as mean \pm standard error of mean (S.E.M). Statistical analysis was accomplished making use of two-way analysis of variance (ANOVA) test, followed by Bonferroni posttest, using GraphPad Prism 5. The value of significant difference was considered at $\mathrm{p}<0.05$.

\section{Results}

The anti-arthritic effect of E. gerardiana aqueous ethanolic extract and its fractions was appraised against egg albumin denaturation (Figure 1). Plant extract and fractions displayed noteworthy $(\mathrm{p}<0.001)$ egg albumin denaturation inhibition in a concentration-dependent manner (50-6400 $\mu \mathrm{g} / \mathrm{mL})$. The hydro-alcoholic extract at $6400 \mu \mathrm{g} / \mathrm{mL}$ offered $3219.4 \%$ inhibition and among the fractions, aqueous fraction proved to be most efficacious with $2899.3 \%$ egg albumin denaturation inhibition at $6400 \mu \mathrm{g} / \mathrm{mL}$. Though, diclofenac sodium

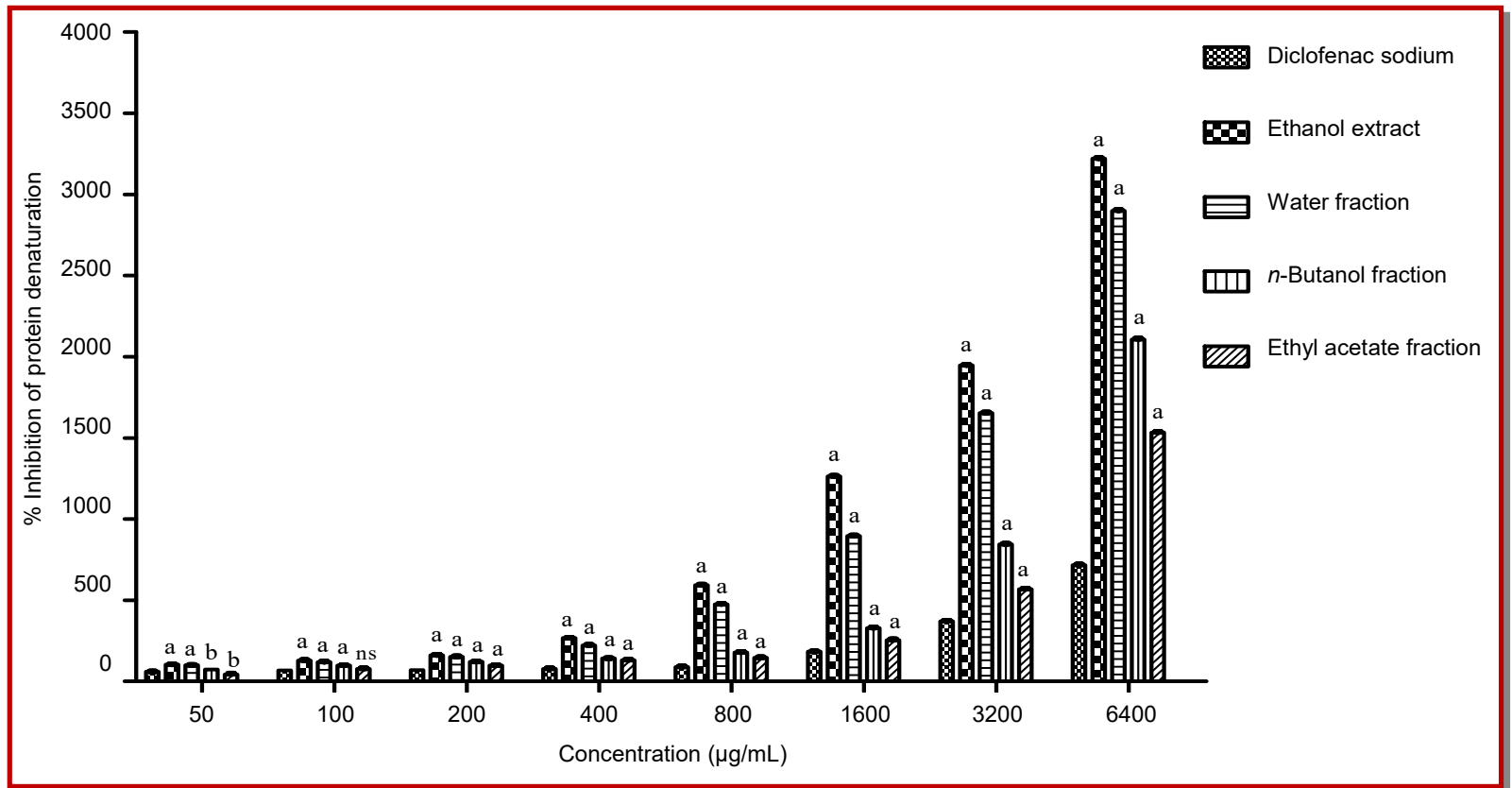

Figure 1: Effect of E. gerardiana on inhibition of protein (egg albumin) denaturation. Results are expressed as mean $\pm S E M$ ( $n=3$ ), using two way ANOVA followed by Bonferroni posttest. ap $<0.001,{ }^{b} p<0.05$ when compared to standard 


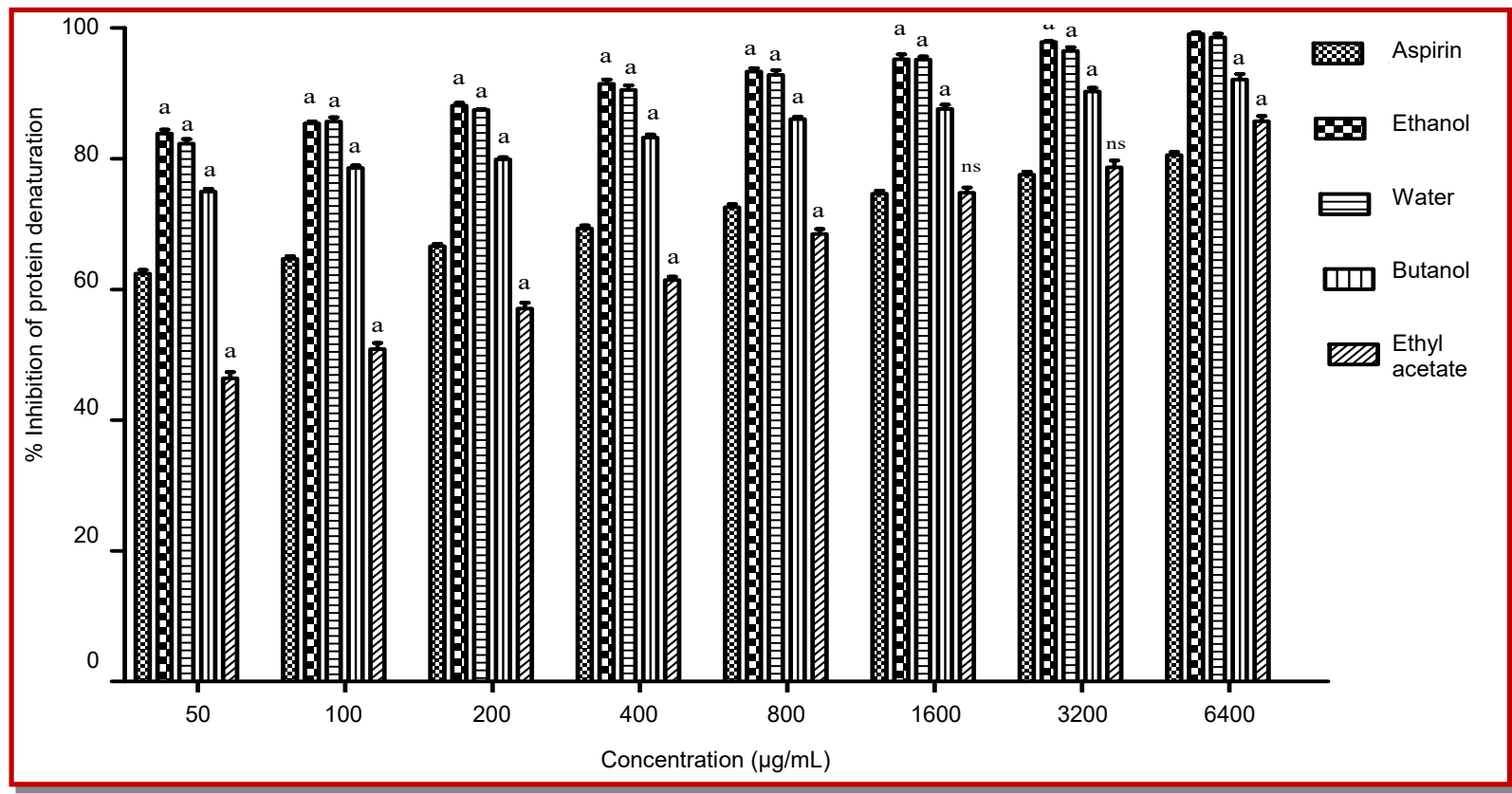

Figure 2: Effect of EG on inhibition of protein (BSA) denaturation. Results are expressed as mean \pm SEM ( $n=3$ ), using two way ANOVA followed by Bonferroni posttest. a $\mathrm{p}<0.001$, nsnon-significant when compared to standard

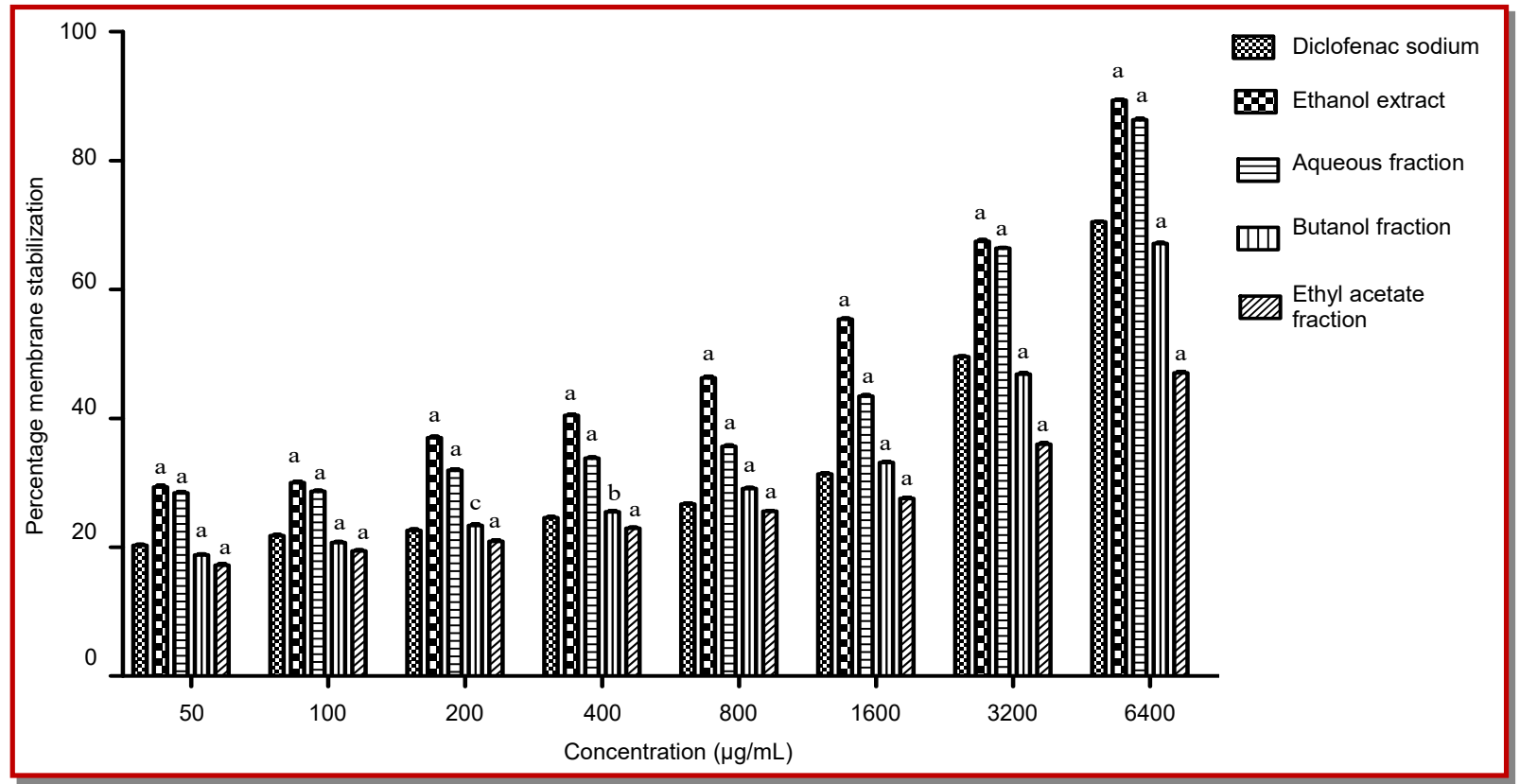

Figure 3: Effect of Ephedra gerardiana on human red blood cell membrane stabilization. Results are expressed as mean \pm SEM $(n=3)$, using two way ANOVA followed by Bonferroni posttest. a $p<0.001, b p<0.01, c p<0.05$ when compared to standard.

exhibited concentration-dependent protein denaturation inhibition but it showed less effect compared to crude extract and fractions of E. gerardiana at similar concentrations.

Similarly, concentrations ranging from 50-6400 $\mu \mathrm{g} / \mathrm{mL}$ were tested to find out the inhibitory percentage of BSA denaturation using aspirin as a standard. A significant concentration dependent rise $(p<0.001)$ in percentage inhibition was detected for all the concentrations tested, with a dose-dependent upsurge in anti-arthritic activity (Figure 2). Results depicted $99.1 \%$ impediment of BSA at $6400 \mu \mathrm{g} / \mathrm{mL}$ of crude extract. Nonetheless, aqueous fraction produced maximum inhibitory effect than $n$ butanol and ethyl acetate fractions i.e., 98.5, 92.1 and $85.7 \%$, correspondingly at $6400 \mu \mathrm{g} / \mathrm{mL}$. The effect of extract and fractions at $6400 \mu \mathrm{g} / \mathrm{mL}$ was more pronounced than aspirin (80.5\%).

In human red blood cell membrane stabilization test, 


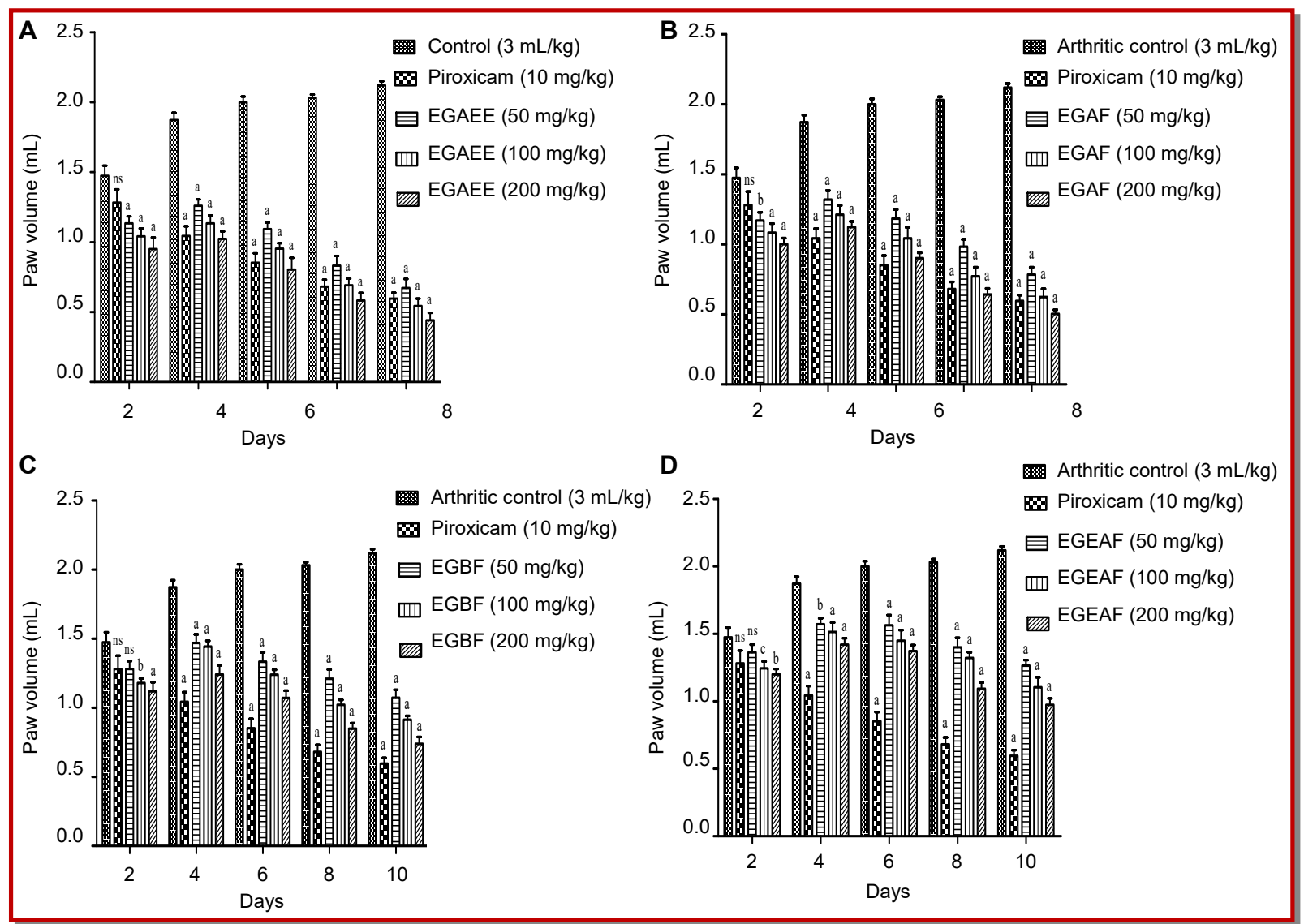

Figure 4: Effect of E. gerardiana extract and fractions: (A) Aqueous ethanolic extract, (B) Aqueous fraction, (C) n-butanol fraction, (D) Ethyl acetate fraction) on paw volume of formaldehyde induced arthritic rats. ap $<0.001,{ }^{b} p<0.01$, ${ }^{c} p<0.05$, nsnon-significant when compared to arthritic control. EGAEE $=$ E. gerardiana aqueous ethanolic extract, EGAF= E. gerardiana aqueous fraction, $\mathrm{EGBF}=E$. gerardiana butanol fraction, $\mathrm{EGEAF}=E$. gerardiana ethyl acetate fraction

plant extract and its fractions notably protected erythrocyte membrane against lysis induced by heat and hypotonic solution in a concentration dependent manner (50-6400 $\mathrm{gg} / \mathrm{mL}$ ) (Figure 3). Plant extract, aqueous, $n$-butanol and ethyl acetate fractions at 6400 $\mu \mathrm{g} / \mathrm{mL}$ concentration showed maximum protection of human red blood cell in hypotonic solution i.e., 89.3, $86.3,67.1$ and $47.0 \%$, in that order. All the results were compared with diclofenac at same concentrations, which showed $70.4 \%$ protection of human red blood cell in hypotonic solution at $6400 \mu \mathrm{g} / \mathrm{mL}$.

The anti-arthritic potential was also appraised in vivo using formaldehyde prompted arthritis in rats. Sub planter injection of formaldehyde in arthritic control group showed substantial increase in paw volume and diameter throughout the study period. The assessment made on $10^{\text {th }}$ day presented that treatment with 200 $\mathrm{mg} / \mathrm{kg}$ of plant extract, aqueous, $n$-butanol and ethyl acetate fractions considerably $(\mathrm{p}<0.001)$ decreased injected hind paw volume i.e., 79.1, 76.2, 65.0, 54.0 (Figure 4) and paw diameter i.e., 75.0, 73.6, 61.0 and $50.9 \%$ (data not shown), respectively as compared with arthritic control group. However, piroxicam $(10 \mathrm{mg} / \mathrm{kg})$ treated animals exhibited 71.8 and $70.6 \%$ inhibition of paw volume and diameter, correspondingly on $10^{\text {th }}$ day.

\section{Discussion}

The outcomes of existing study have discovered dosedependent anti-arthritic potential of aqueous ethanolic extract, aqueous, $n$-butanol and ethyl acetate fractions of E. gerardiana in both in vitro and in vivo techniques. The in vitro methods used to check anti-arthritic activity included inhibition of BSA and fresh hen's egg albumin denaturation and membrane stabilization assay, while in vivo method involved formaldehyde induced arthritis in rats.

Preceding investigations have stated that protein denaturation is the principal cause of inflammatory and arthritic disorders that proceed to auto-antigens generation thus, resulting in rheumatic disorders. The denaturation possibly implicates variation in hydrogen, electrostatic, disulphide and hydrophobic bonds (Gautam et al., 2013). Numerous anti-inflammatory 
drugs dose dependently deter thermally prompted protein denaturation (Menon et al., 2011). Therefore, substances which can avert denaturation of protein would be considered valuable for developing antiarthritic drugs. In the current analysis, hydro-alcoholic extract and fractions of E. gerardiana markedly subdued protein denaturation (BSA and egg albumin) and results were more pronounced than standard drug. From the findings, it could be concluded that $E$. gerardiana is capable of subsiding auto-antigens production, which circuitously reduces protein denaturation and hence relieves arthritis.

The membrane of erythrocytes is analogous to membrane of lysosomes and stabilization of human red blood cell from hypotonicity instigated lysis can be allied with anti-arthritic property of drug. The hypotonic solution causes rupturing of lysosomal membrane, consequently bringing about release of lysosomal enzymes (bacterial enzymes and proteases) and phospholipase A2 that recruits the generation of inflammatory intermediaries. Hence, stabilization of red blood cell membrane obviates the liberation of inflammatory intermediaries, which diminishes cell rupture and tissue injury (Alamgeer et al., 2015). Some NSAIDS and glucocorticoids stabilize lysosomes in tissue cells and thereby preclude the discharge of lysosomal enzymes into cytoplasm of cells, thus avoiding deterioration (Udavant et al., 2012). E. gerardiana and its fractions notably repressed hypotonicity induced human red blood cell hemolysis in concentration dependent manner, compared with diclofenac sodium. The findings of present work suggest membrane stabilization as an additional mechanism of anti-arthritic effect of E. gerardiana, which might be due to direct interaction of phytoconstituents with membrane components such as proteins, albeit, exact mechanism of membrane stabilization is not documented.

Formaldehyde-induced arthritis is a most apposite model for screening an agent with plausible antiarthritic, anti-inflammatory and anti-proliferative activity, as it resembles human arthritis (Ben et al., 2016). Formaldehyde tempts arthritis by denaturing proteins at the site of injection, which primes to development of an immunological response against degraded products (Nair et al., 2012). Moreover, formaldehyde persuaded arthritis is biphasic in nature i.e., it expresses neurogenic components, which influence brain activity and then lead to tissuemediated reaction. Neurogenic phase directly excites paw engorgement together with centrally interceded effects of pain via the discharge of pain intermediaries in later phase (Owoyele et al., 2011). The primary stage of edema is attributable to liberation of histamine, serotonin and kinin-like substances while, second accelerating phase of edema formation may be owing to prostaglandin like substances release (Shaikh, 2011). Earlier studies assert that agents that act on CNS impede both stages equally, though peripherally working substances obstruct later stage (Alamgeer et al., 2017). The reduction in paw volume and diameter detected in formaldehyde model may be due to the conceivable mechanism of E. gerardiana to inhibit these chemical mediators of inflammation. The marked decline in paw volume and diameter was presented by $200 \mathrm{mg} / \mathrm{kg}$ of crude extract and its aqueous fraction. Moreover, E. gerardiana extract and fractions inhibited both phases of inflammation, therefore it acts centrally.

Ephedra species contain alkaloids such as ephedrine, norephedrine, methylephedrine, pseudoephedrine, norpseudoephedrine, and methylpseudoephedrine. Besides, in some Eurasian Ephedra species ephedroxane and ephedradine A-D, have been found. Ephedra genus also comprises flavonoids (leucoanthocyanidin, leucopelargonine, leucodelphinidin, lucenine, vicenin-1 and 2), tannins and benzylmethylamine (Ibragic and Sofić, 2015). In addition, phytochemical investigations and review of literature shown the existence of flavonoids, alkaloids, terpenoids, saponins and glycosides in E. gerardiana stem (Jamil et al., 2012). Also, formerly in DPPH test, E. gerardiana leaf extract has shown anti-oxidant activity with $13.3 \pm 0.6 \mu \mathrm{g} / \mathrm{mL} \mathrm{IC}_{50}$ value (Kumar and Singh, 2011). Among the aforementioned constituents, saponins and alkaloids are recognized to reduce arthritic index, prevent articular swelling and control IL-1 $\beta$ and TNF- $\alpha$ levels in inflammatory tissues of arthritic rats. Flavonoids are often used for their anti-oxidant effect against free radicals and also possess anti-inflammatory properties (Fatima and Fatima, 2016). Hence, it can be proposed that anti-arthritic activity of E. gerardiana hydroalcoholic extract and fractions could be due to combined effect of alkaloids, flavonoids, saponins and anti-oxidant property of E. gerardiana. The presence of these compounds in extract can strongly support antiarthritic potential of E. gerardiana and its use in traditional alternative and complementary medicine.

\section{Conclusion}

E. gerardiana may serve as an effective anti-arthritic drug and effect may be speculated owing to its phytoconstituents.

\section{Ethical Issue}

The study protocol was approved by Institutional Animal Ethics Committee, Faculty of Pharmacy, University of Sargodha (Approval No. 51A45 IEC UOS). The animals were treated according to standard procedures guided by National Research Council (NRC, 1996). 


\section{Conflict of Interest}

The authors declare no conflicts of interest.

\section{Acknowledgement}

The authors acknowledge University of Sargodha for providing some financial support for this study.

\section{References}

Alamgeer, Hasan UH, Uttra AM, Rasool S. Evaluation of in vitro and in vivo anti-arthritic potential of Berberis calliobotrys. Bangladesh J Pharmacol. 2015; 10: 807-19.

Alamgeer, Naz H, Rasool S, Raza SA, Ahmad T, Ahsan H, Mushtaq MN, Asif H, Khan Z, Noor N, Utra AM, Hassan UH. Anti-inflammatory, analgesic and antipyretic activities of the aqueous methanolic extract of Berberis calliobotrys in albino mice. Acta Pol Pharm. 2016; 73: 717-23.

Alamgeer, Niazi SG, Uttra AM, Qaiser MN, Ahsan H. Appraisal of anti-arthritic and nephroprotective potential of Cuscuta reflexa. Pharm Biol. 2017; 55: 792-98.

Ben IO, Etim OE, Udo NM. Anti-inflammatory effects of Napoleona imperialis P. Beauv. (Lecythidaceae) on rat model of inflammation. Indian J Health Sci. 2016; 9: 89-95.

Fatima N, Fatima SJ. Pharmacological screening for antiarthritic activity of Moringa oleifera. Asian J Pharm Clin Res. 2016; 9: 106-11.

Gautam RK, Sharma S, Sharma K. Comparative evaluation of anti-arthritic activity of Pongamia pinnata (Linn.) Pierre and Punica granatum Linn.: An in vitro study. Int J Pharm Pharm Sci. 2013; 5: 721-24.

Gorsi MS, Miraj S. Ethnomedicinal survey of plants of Khanabad village and its allied areas, District Gilgit. Asian J Plant Sci. 2002; 1: 604-15.

Ibragic S, Sofić E. Chemical composition of various Ephedra species. Bosn J Basic Med Sci. 2015; 15: 21-27.
Jamil M, Mirza B, Yasmeen A, Khan MA. Pharmacological activities of selected plant species and their phytochemical analysis. J Med Plants Res. 2012; 6: 5013-22.

Kumar GP, Singh SB. Antibacterial and anti-oxidant activities of ethanol extracts from trans Himalayan medicinal plants. Eur J Appl Sci. 2011; 3: 53-57.

Menon DB, Sasikumar JM, Latha K. Anti-inflammatory and cytotoxic activity of methanolic extract of Plectranthus hadiensis stem. Pharmacol Online. 2011; 3: 275-82.

Nair V, Singh S, Gupta YK. Evaluation of disease modifying activity of Coriandrum sativum in experimental models. Indian J Med Res. 2012; 135: 240-45.

Nair V, Singh S, Gupta YK. Evaluation of the disease modifying activity of Colchicum luteum Baker in experimental arthritis. J Ethnopharmacol. 2011; 133: 303-07.

Narayani PC, Anbu J, Vasuki R, Hari R. In vitro and in vivo anti -arthritic activity of combined ethanolic extracts of Calotropis gigantea and Cardiospermum halicacabum in Wistar rats. J Nat Remedies. 2014; 14: 58-66.

NRC. Guide for the care and use of laboratory animals. Washington DC, National Academy Press, 1996.

Owoyele BV, Adenekan OT, Soladoye AO. Effects of honey on inflammation and nitric oxide production in Wistar rats. Zhong Xi Yi Jie He Xue Bao. 2011; 9: 447-52.

Qureshi RA, Ghufran MA, Sultana KN, Ashraf M, Khan AG. Ethnobotanical studies of medicinal plants of Gilgit district and surrounding areas. Ethnobot Res Appl. 2006; 5: 115-22.

Ratsch C. The encyclopedia of psychoactive plants: Ethnopharmacology and its applications. Rochester, Park Street Press, 1998

Shaikh PZ. Study of anti-inflammatory activity of ethanolic extract of Hemidesmus indicus roots in acute, subchronic and chronic inflammation in experimental animals. Int J Pharm Life Sci. 2011; 2: 1154-73.

Udavant PB, Satyanarayana SV, Upasani CD. Preliminary screening of Cuscuta reflexa stems for anti-inflammatory and cytotoxic activity. Asian Pac J Trop Biomed. 2012; 2012: S1303-07.

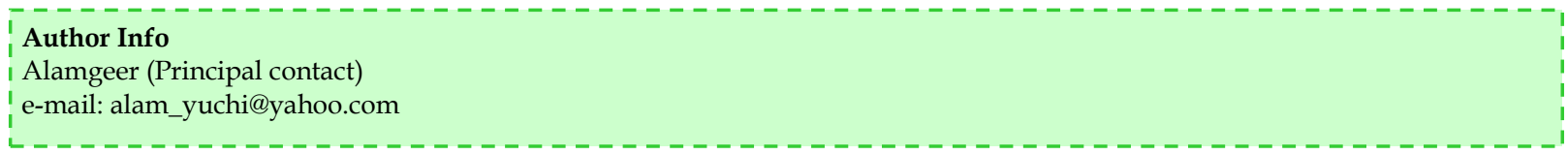

